\title{
Levels of acute inflammatory biomarkers in advanced prostate cancer patients with $\alpha_{2}$-macroglobulin deficiency
}

\author{
YUHSAKU KANOH $^{1}$, HIDEKI OHTANI $^{1}$, SHIN EGAWA $^{2}$, SHIRO BABA $^{3}$ and TOHRU AKAHOSHI ${ }^{4}$ \\ Departments of ${ }^{1}$ Laboratory Medicine, ${ }^{3}$ Urology and ${ }^{4}$ General Medicine, School of Medicine, Kitasato University, \\ 1-15-1 Kitasato, Sagamihara, Minami-ku, Kanagawa 252-0374; ${ }^{2}$ Department of Urology, School of Medicine, \\ Jikei University, 3-19-18 Nishishinbashi, Minato-ku, Tokyo 105-8471, Japan
}

Received June 30, 2011; Accepted August 8, 2011

DOI: $10.3892 /$ ijo.2011.1185

\begin{abstract}
C-reactive protein (CRP), serum amyloid A (SAA), interleukin-6 (IL-6), $\alpha 1$-antitrypsin ( $\alpha 1 \mathrm{AT}$ ), $\alpha 1$-acid glycoprotein $(\alpha 1 \mathrm{AG})$ and ceruloplasmin $(\mathrm{CP})$ are acute inflammatory biomarkers that increase in various conditions including infection, inflammation, malignancy and tissue disturbance. In contrast, $\alpha_{2}$-macroglobulin $(\alpha 2 \mathrm{M})$ is involved in inflammation through its function as a carrier protein of IL-6. We had previously reported on advanced prostate cancer $(\mathrm{PCa})$ patients with multiple distant bone metastases in whom serum $\alpha 2 \mathrm{M}$ levels were markedly decreased ( $\alpha 2 \mathrm{M}$ deficiency). However, the relationship between serum levels of $\alpha 2 \mathrm{M}$ and acute inflammatory biomarkers in $\mathrm{PCa}$ patients with or without $\alpha 2 \mathrm{M}$ deficiency has not been demonstrated. In the present study, we examined serum levels of CRP, SAA, IL-6, $\alpha 1 \mathrm{AT}, \alpha 1 \mathrm{AG}$ and CP in PCa patients with or without $\alpha 2 \mathrm{M}$ deficiency to establish clinical significance and changes in these biomarkers during $\mathrm{PCa}$ disease progression. We found that upon addition of recombinant IL-6 (rIL-6) to serum from PCa patients with $\alpha 2 \mathrm{M}$ deficiency, since a function of $\alpha 2 \mathrm{M}$ is to bind and stabilize IL-6, the $\alpha 2 \mathrm{M}-\mathrm{IL}-6$ complex and free endogenous IL-6 were not detectable. Serum levels of the $\alpha 2 \mathrm{M}$-independent markers, $\alpha 1 \mathrm{AT}, \alpha 1 \mathrm{AG}$ and $\mathrm{CP}$, in all PCa patients regardless of $\alpha 2 \mathrm{M}$ deficiency were significantly higher than in healthy controls, but those of the $\alpha 2 \mathrm{M}$-dependent molecules, CRP, SAA and IL-6, were not increased in PCa patients with $\alpha 2 \mathrm{M}$ deficiency. Therefore, quantitation of both $\alpha 2 \mathrm{M}$-dependent (CRP, SAA and IL- 6 ) and $\alpha 2 \mathrm{M}$-independent ( $\alpha 1 \mathrm{AT}, \alpha 1 \mathrm{AG}$ and $\mathrm{CP}$ ) acute inflammatory biomarkers in advanced PCa patients may be an auxiliary indicator, together with prostate-specific antigen (PSA), to monitor PCa disease progression.
\end{abstract}

Correspondence to: Dr Yuhsaku Kanoh, Department of Laboratory Medicine Kitasato University School of Medicine, 1-15-1 Kitasato, Sagamiharaminami-ku, Kanagawa 252-0374, Japan

E-mail: kanoh@med.kitasato-u.ac.jp

Key words: C-reactive protein, serum amyloid A, interleukin-6, $\alpha 1$-antitrypsin, $\alpha 1$-acid glycoprotein, ceruloplasmin, $\alpha_{2}$-macroglobulin, prostate-specific antigen

\section{Introduction}

$\alpha_{2}$-macroglobulin $(\alpha 2 \mathrm{M})$ is the most abundant proteinase inhibitor in the blood and inhibits the activity of various proteases through direct interaction. Moreover, a major biological function of $\alpha 2 \mathrm{M}$ is as a carrier protein for interleukin-6 (IL-6) or growth hormone $(1,2)$. Therefore, $\alpha 2 \mathrm{M}$ is involved in coagulation, fibrinolytic activity and inflammatory reaction in vivo. Serum $\alpha 2 \mathrm{M}$ levels generally increase in various disorders, such as nephrotic syndrome, inflammatory diseases and malignancy. On the other hand, it is also known that serum $\alpha 2 \mathrm{M}$ levels decrease in very few disorders such as disseminated intravascular coagulation (DIC) and hematologic malignancy. We had previously reported on advanced prostate cancer (PCa) with multiple distant bone metastases, in whom serum $\alpha 2 \mathrm{M}$ levels were markedly decreased to $<20 \mathrm{mg} / \mathrm{dl}(\alpha 2 \mathrm{M}$ deficiency), while serum prostate-specific antigen (PSA) levels were greatly increased $(3,4)$. These cases were not complicated by DIC.

IL-6, C-reactive protein (CRP) and serum amyloid A (SAA) are widely used as acute inflammatory biomarkers in various conditions such as infection, inflammation, malignancy and tissue disturbance (5-7). IL-6 is a multi-functional cytokine that regulates the production of CRP and SAA in liver cells in various conditions $(8,9)$. CRP is most widely used as a sensitive inflammatory biomarker in routine clinical examination. SAA exists as a high density lipoprotein (HDL)-complex with a molecular weight of $200-400 \mathrm{kDa}$, which is generally increased in patients with viral infection or in corticosteroidtreated patients in contrast to CRP $(6,10)$.

$\alpha 1$-antitrypsin $(\alpha 1 \mathrm{AT})$ is a plasma glycoprotein, which inhibits the activity of proteases, such as trypsin and elastase, derived from macrophage or pancreas cells. $\alpha 1$-acid glycoprotein $(\alpha 1 \mathrm{AG})$ is also a plasma glycoprotein that inhibits the activity of progesterone. Ceruloplasmin (CP) is a copperbinding protein and is involved in metabolism of copper or iron.

It is thought that $\alpha 2 \mathrm{M}$ is involved in inflammatory reaction through its function as a carrier protein of IL-6 (1). Furthermore, it has been suggested that the concentration of $\alpha 2 \mathrm{M}$ affects the levels of IL-6, CRP and SAA produced by liver cells through its regulation of IL-6. However, the relationship between serum levels of $\alpha 2 \mathrm{M}$ and acute inflammatory biomarkers in PCa 
patients with or without $\alpha 2 \mathrm{M}$ deficiency has not been demonstrated. Therefore, we quantified serum levels of CRP, SAA, IL-6, $\alpha 1 \mathrm{AT}, \alpha 1 \mathrm{AG}$ and CP in PCa patients with or without $\alpha 2 \mathrm{M}$ deficiency to establish the clinical significance and changes of these acute inflammatory biomarkers during PCa disease progression. Although this study includes only a limited number of PCa patients, it is the first report to investigate the clinical significance and changes of acute inflammatory biomarkers in $\mathrm{PCa}$ patients with regard to $\alpha 2 \mathrm{M}$ deficiency.

\section{Materials and methods}

Subjects. Forty-three untreated adult men participated in this study, of whom 10 were healthy controls (mean age 62.8 years, range 52-70) and 33 were diagnosed with prostatic disease at the Kitasato University Hospital. The thirty-three patients had $\mathrm{PCa}$ at stage M1b (mean age 67.8 years, range 55-79) without inflammatory disorders. $\alpha 2 \mathrm{M}$ deficiency was defined as serum $\alpha 2 \mathrm{M}$ levels $<20 \mathrm{mg} / \mathrm{dl}$ and there was no precipitation line of $\alpha 2 \mathrm{M}$ on immunoelectrophoresis with anti-whole human serum and antiserum to $\alpha 2 \mathrm{M}$ in routine examination. These patients also had markedly increased serum PSA levels and multiple distant bone metastases. The histological diagnoses in the patients were confirmed by six-sextant biopsy and/or transurethral resection in all cases. PCa was staged clinically following the TNM classification (11). Briefly, stage T1 is defined as tumor not clinically recognizable and identifiable only by histological examination of prostatic tissue. Stage T2 tumors are palpable but confined within the prostate. Stage T3 tumors are palpable and extend through the prostatic capsule with unilateral or bilateral extension. The M1 stage is defined by the presence of distant metastasis and M1b by bone metastasis. Serum samples were obtained from these patients and stored at $-80^{\circ} \mathrm{C}$ until use.

Ethical approval. The study was conducted in accordance with the Declaration of Helsinki. This study had no influence on the management of patients, and informed consent was obtained from all subjects.

Acute inflammatory biomarkers. Measurement of $\alpha 2 \mathrm{M}, \alpha 1 \mathrm{AT}$, $\alpha 1 \mathrm{AG}$ and CP levels in serum was performed by laser nephelometry using a Behring Nephelometer Analyzer (Behring Diagnostics, Westwood, MA). CRP and SAA levels in serum were measured by latex nephelometry using the LX-M (Eiken Chemical Co., Japan). IL-6 levels in serum were measured by a specific luminescence sandwich-type enzyme-linked immunosorbent assay (ELISA), using a previously described method with modifications (12). The assay employed 2 monoclonal anti-human IL-6 antibodies (clones IG61 and IG67; Toray, Tokyo, Japan) and alkaline phosphatase with the chemiluminescent substrate Lumi-phos (Lumigen Inc., Detroit, MI) and was sensitive to $0.5 \mathrm{pg} / \mathrm{ml}$.

Bone scintigraphy. Bone metastasis in PCa patients was diagnosed by bone scintigraphy using ${ }^{99 \mathrm{~m}} \mathrm{Tc}$-labeled methylene diphosphonate ( $\left.{ }^{99 m} \mathrm{Tc}-\mathrm{MDP}\right)$.

Western blotting. Binding assays for purified $\alpha 2 \mathrm{M}$ (Protogen AG, Laufelfingen, Switzerland) and recombinant IL-6 (rIL-6)
(Genzyme, Cambridge, MA) were analyzed by Western blotting with 5-15\% SDS-polyacrylamide gel electrophoresis and staining with anti-IL-6 sera (Dako, Glostrup, Denmark) according to the Laemmli method (13). $\alpha 2 \mathrm{M}$ and IL-6 of 1:1 molar concentrations were mixed and incubated for $20 \mathrm{~min}$ at $37^{\circ} \mathrm{C}$.

High performance liquid chromatography. We analyzed the IL-6 elution profiles of a mixture of purified $\alpha 2 \mathrm{M}(50 \mu \mathrm{g})$ and rIL-6 $(2 \mu \mathrm{g})$ or serum $(10 \mu \mathrm{l})$ from patients with $\alpha 2 \mathrm{M}$ deficiency mixed with rIL-6 $(2 \mu \mathrm{g})$ by high performance liquid chromatography (HPLC). Fractionation of serum samples was performed by HPLC using a TSKG-3000 SWXL (Tosoh, Tokyo, Japan) column, and IL-6 level in each fraction was measured. Flow rate was $1 \mathrm{ml} / \mathrm{min}$ and fractions of $0.5 \mathrm{ml}$ volume were collected. The column was calibrated using $20 \mathrm{mM}$ phosphate buffer (pH 7.5).

Statistical analysis. The Wilcoxon and the Mann-Whitney U-tests were used for statistical analyses, and $\mathrm{p}<0.05$ was considered statistically significant.

\section{Results}

Concentrations of $\alpha 2 M, C R P, S A A, I L-6, \alpha 1 A T, \alpha 1 A G$ and $C P$ in serum. Table I shows the concentrations (mean $\pm \mathrm{SD}$ ) of CRP, SAA, IL-6, $\alpha 1 \mathrm{AT}, \alpha 1 \mathrm{AG}$ and CP in the sera of healthy controls and $\mathrm{PCa}$ patients with or without $\alpha 2 \mathrm{M}$ deficiency. $\alpha 2 \mathrm{M}$ deficiency was defined as serum $\alpha 2 \mathrm{M}$ levels $<20 \mathrm{mg} / \mathrm{dl}$. The serum levels of CRP (Fig. 1), SAA (Fig. 2) and IL-6 (Fig. 3) in $\mathrm{PCa}$ patients without $\alpha 2 \mathrm{M}$ deficiency were significantly higher than in healthy controls and PCa patients with $\alpha 2 \mathrm{M}$ deficiency (all $\mathrm{p}<0.01$ ). On the other hand, serum levels of $\alpha 1 \mathrm{AT}$ (Fig. 4), $\alpha 1 \mathrm{AG}$ (Fig. 5) and CP (Fig. 6) in PCa patients with or without $\alpha 2 \mathrm{M}$ deficiency were significantly higher than in healthy controls $(\mathrm{p}<0.05)$. However, there was no significant difference between PCa patients with and without $\alpha 2 \mathrm{M}$ deficiency.

Western blotting for $\alpha 2 M$ and IL- 6 complex. To verify the detection and size of the $\alpha 2 \mathrm{M}-\mathrm{IL}-6$ complex, purified $\alpha 2 \mathrm{M}$ and rIL-6 were mixed, and the complex was identified using Western blotting as a band of $\sim 800 \mathrm{kDa}$ (Fig. 7).

IL-6 elusion profiles of mixture of purified $\alpha 2 M$ and $r I L-6$, and serum from patients with $\alpha 2 M$ deficiency mixed with rIL- 6 . Fig. 8 shows the IL- 6 elution profiles of a mixture of purified $\alpha 2 \mathrm{M}$ and rIL-6 (dots) and of serum from patients with $\alpha 2 \mathrm{M}$ deficiency mixed with rIL-6 (triangles) by HPLC. Three peaks were identified from the mixture of purified $\alpha 2 \mathrm{M}$ and rIL-6: the first peak at $800 \mathrm{kDa}$ corresponding to the $\alpha 2 \mathrm{M}$-IL6 complex; a second peak at $\sim 50 \mathrm{kDa}$ corresponding to a polymer of IL-6; and a third peak at $\sim 20 \mathrm{kDa}$ representing free IL-6. When the serum from PCa patients with $\alpha 2 \mathrm{M}$ deficiency was mixed with rIL- 6 the first and third peaks corresponding to $\alpha 2 \mathrm{M}-\mathrm{IL}-6$ complex and free IL-6, respectively, were undetectable.

\section{Discussion}

CRP, SAA, IL-6, $\alpha 1 \mathrm{AT}, \alpha 1 \mathrm{AG}$ and CP are known as acute inflammatory biomarkers that increase in various conditions such as infection, inflammation, malignancy and tissue 
Table I. Concentration (mean $\pm \mathrm{SD}$ ) of $\alpha_{2}$-macroglobulin $(\alpha 2 \mathrm{M})$, C-reactive protein (CRP), serum amyloid A (SAA), interleukin-6 (IL-6), $\alpha 1$ anti-chymotripsin ( $\alpha 1 \mathrm{AT}), \alpha 1$ acid glycoprotein $(\alpha 1 \mathrm{AG})$ and ceruloplasmin $(\mathrm{CP})$ in sera of healthy controls and advanced prostate cancer (PCa) patients with or without $\alpha 2 \mathrm{M}$ deficiency.

Advanced PCa patients

Healthy controls $(n=10)$

without $\alpha 2 M$ deficiency $(n=23)$

with $\alpha 2 \mathrm{M}$ deficiency $(\mathrm{n}=10)$

\begin{tabular}{lccc}
\hline$\alpha 2 \mathrm{M}(\mathrm{mg} / \mathrm{dl})$ & $151.7 \pm 25.30$ & $252.45 \pm 125.07^{\mathrm{a}}$ & $12.75 \pm 5.60^{\mathrm{b}}$ \\
$\mathrm{CRP}(\mu \mathrm{g} / \mathrm{dl})$ & $109.58 \pm 89.66$ & $1534.6 \pm 1482.8^{\mathrm{a}}$ & $173 \pm 90.3^{\mathrm{b}}$ \\
$\mathrm{SAA}(\mu \mathrm{g} / \mathrm{ml})$ & $9.96 \pm 4.16$ & $54.7 \pm 44.5^{\mathrm{a}}$ & $2.15 \pm 1.68^{\mathrm{b}}$ \\
$\mathrm{IL}-6(\mathrm{pg} / \mathrm{ml})$ & $7.58 \pm 6.0$ & $46.50 \pm 40.65^{\mathrm{a}}$ & $3.38 \pm 2.61^{\mathrm{b}}$ \\
$\alpha 1 \mathrm{AT}(\mathrm{mg} / \mathrm{dl})$ & $122 \pm 28.0$ & $293.76 \pm 68.51^{\mathrm{c}}$ & $305.71 \pm 71.30^{\mathrm{c}}$ \\
$\alpha 1 \mathrm{AG}(\mathrm{mg} / \mathrm{dl})$ & $67.5 \pm 25.5$ & $102 \pm 39.36^{\mathrm{c}}$ & $100.8 \pm 38.90^{\mathrm{c}}$ \\
$\mathrm{CP}(\mathrm{mg} / \mathrm{dl})$ & $29.0 \pm 8.0$ & $37.74 \pm 10.93^{\mathrm{c}}$ & $37.6 \pm 10.89^{\mathrm{c}}$ \\
\hline
\end{tabular}

${ }^{a} \mathrm{p}<0.01$, healthy controls vs. PCa patients without $\alpha 2 \mathrm{M}$ deficiency; ${ }^{\mathrm{b}} \mathrm{p}<0.01$, PCa patients without $\alpha 2 \mathrm{M}$ deficiency vs. PCa patients with $\alpha 2 \mathrm{M}$ deficiency; ${ }^{c} \mathrm{p}<0.05$, healthy controls vs. PCa patients with or without $\alpha 2 \mathrm{M}$ deficiency.

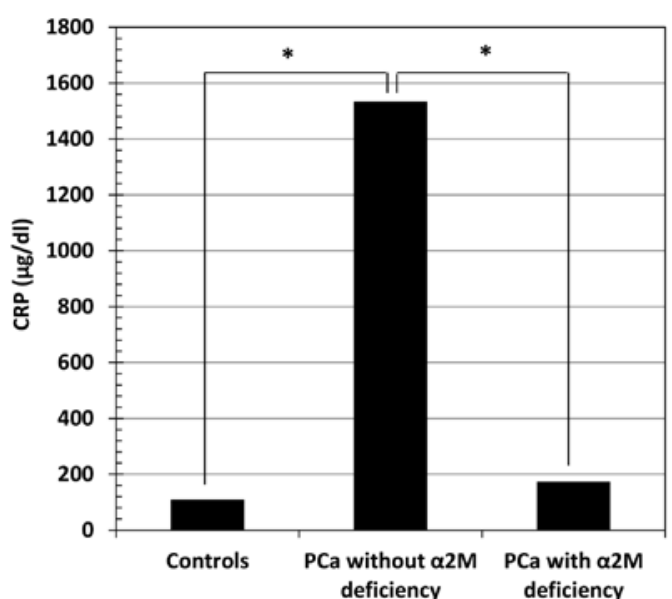

Figure 1. Serum CRP levels in healthy controls and advanced PCa patients with or without $\alpha 2 \mathrm{M}$ deficiency. Serum CRP levels were significantly increased in PCa patients without $\alpha 2 \mathrm{M}$ deficiency as compared with healthy controls and $\mathrm{PCa}$ patients with $\alpha 2 \mathrm{M}$ deficiency. $\mathrm{PCa}$, prostate cancer; ${ }^{\mathrm{p}} \mathrm{p}<0.01$.

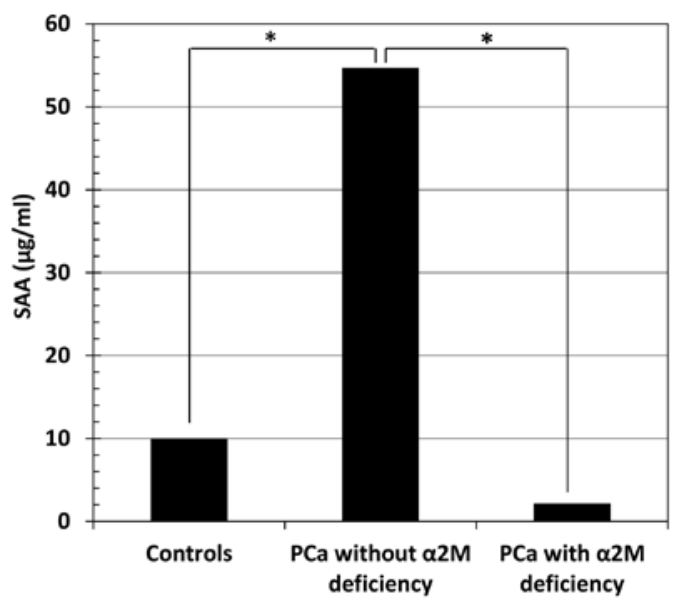

Figure 2. Serum SAA levels in healthy controls and advanced PCa patients with or without $\alpha 2 \mathrm{M}$ deficiency. Serum SAA levels were significantly increased in PCa patients without $\alpha 2 \mathrm{M}$ deficiency as compared with healthy controls and PCa patients with $\alpha 2 \mathrm{M}$ deficiency. PCa, prostate cancer; ${ }^{*} \mathrm{p}<0.01$.

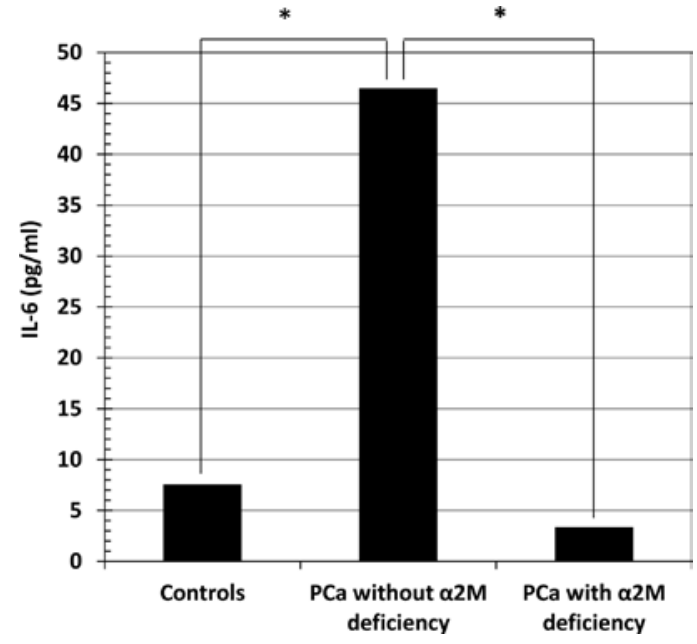

Figure 3. Serum IL-6 levels in healthy controls and advanced PCa patients with or without $\alpha 2 \mathrm{M}$ deficiency. Serum IL-6 levels were significantly increased in PCa patients without $\alpha 2 \mathrm{M}$ deficiency as compared with healthy controls and $\mathrm{PCa}$ patients with $\alpha 2 \mathrm{M}$ deficiency. $\mathrm{PCa}$, prostate cancer; ${ }^{\mathrm{p}} \mathrm{p}<0.01$.

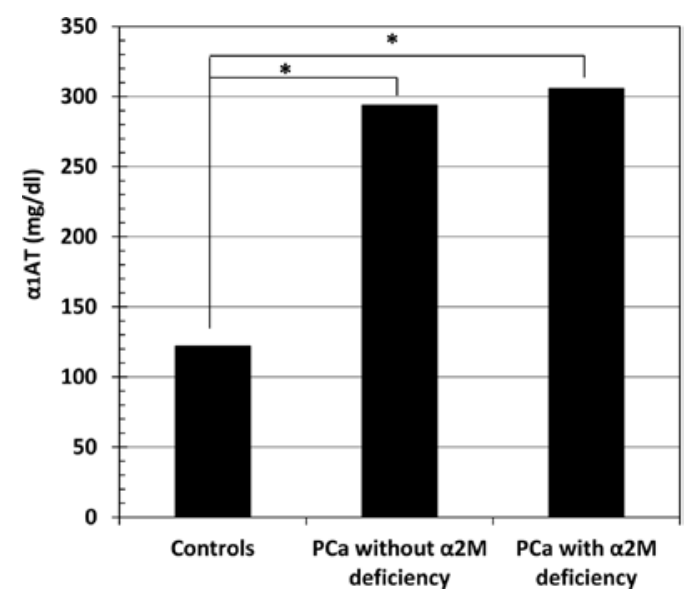

Figure 4. Serum $\alpha 1 \mathrm{AT}$ levels in healthy controls and advanced PCa patients with or without $\alpha 2 \mathrm{M}$ deficiency. Serum $\alpha 1 \mathrm{AT}$ levels were significantly increased in PCa patients with or without $\alpha 2 \mathrm{M}$ deficiency as compared with healthy controls. $\mathrm{PCa}$, prostate cancer; ${ }^{*} \mathrm{p}<0.05$. 


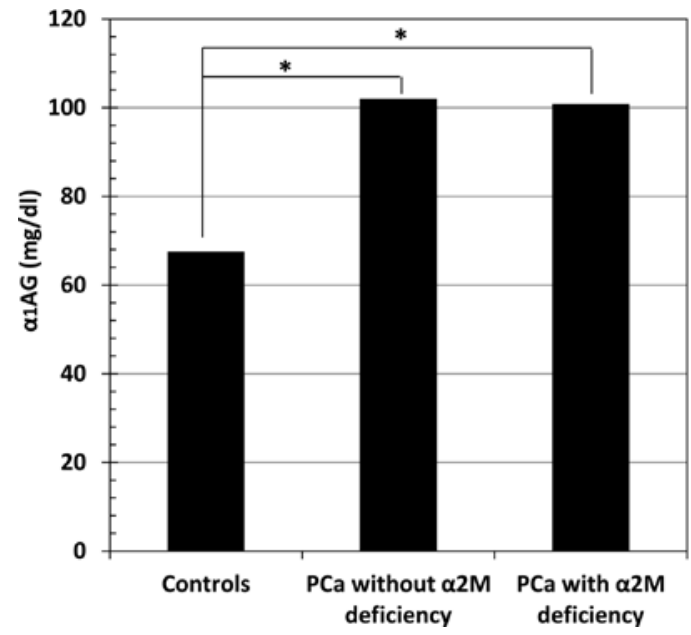

Figure 5. Serum $\alpha 1 \mathrm{AG}$ levels in healthy controls and advanced PCa patients with or without $\alpha 2 \mathrm{M}$ deficiency. Serum $\alpha 1 \mathrm{AG}$ levels were significantly increased in PCa patients with or without $\alpha 2 \mathrm{M}$ deficiency as compared with healthy controls. $\mathrm{PCa}$, prostate cancer; ${ }^{\mathrm{p}} \mathrm{p}<0.05$.

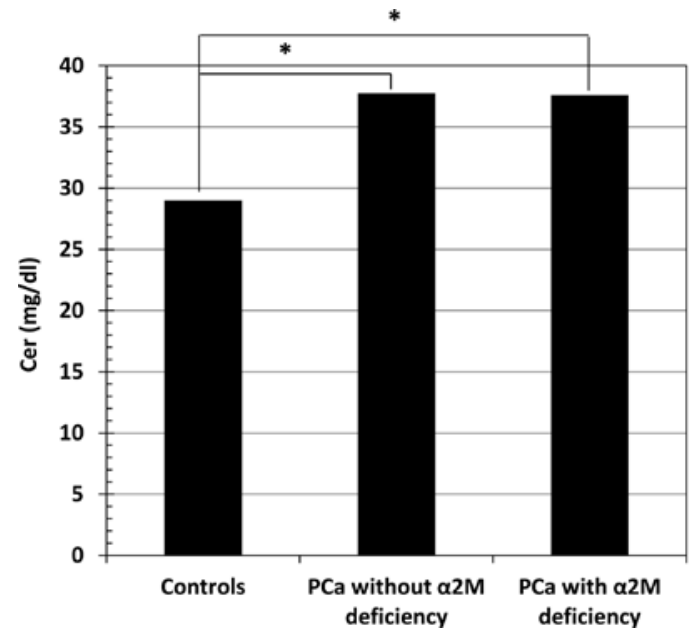

Figure 6. Serum CP levels in healthy controls and advanced PCa patients with or without $\alpha 2 \mathrm{M}$ deficiency. Serum CP levels were significantly increased in $\mathrm{PCa}$ patients with or without $\alpha 2 \mathrm{M}$ deficiency as compared with healthy controls. $\mathrm{PCa}$, prostate cancer; ${ }^{\mathrm{p}}<0.05$.

disturbance $(5-7,14)$. On the other hand, $\alpha 2 \mathrm{M}$ is involved in the inflammatory reaction through its function as a carrier protein of IL-6 which promotes the production of acute inflammatory biomarkers in liver cells (1). Therefore, it has been suggested that the concentration of $\alpha 2 \mathrm{M}$ affects the levels of IL-6, CRP and SAA produced by the liver cells through its regulation of IL-6. We had previously reported on advanced PCa patients with multiple distant bone metastases in whom serum $\alpha 2 \mathrm{M}$ levels were markedly decreased to $<20 \mathrm{mg} / \mathrm{dl}$ ( $\alpha 2 \mathrm{M}$ deficiency) $(3,4)$. However, the relationship between serum levels of $\alpha 2 \mathrm{M}$ and acute inflammatory biomarkers in PCa patients with or without $\alpha 2 \mathrm{M}$ deficiency has not been demonstrated. In this study, we examined serum levels of CRP, SAA, IL-6, $\alpha 1$ AT, $\alpha 1 \mathrm{AG}$ and $\mathrm{CP}$ in PCa patients with or without $\alpha 2 \mathrm{M}$ deficiency to establish clinical significance of these biomarkers during $\mathrm{PCa}$ disease progression. This is the first report that analyzed
KDa

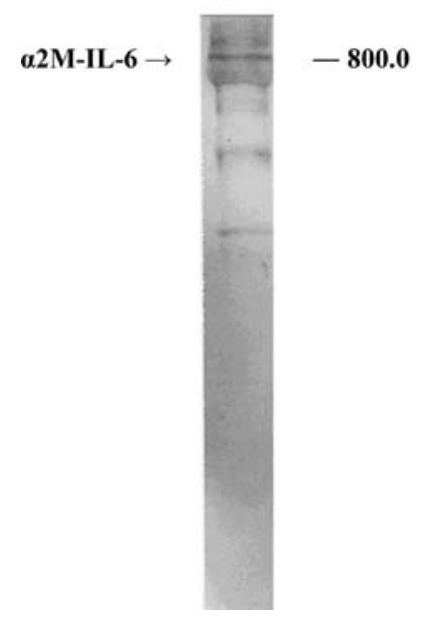

Figure 7. Western blotting for $\alpha 2 \mathrm{M}$ and IL- 6 complex. The band at $\sim 800 \mathrm{kDa}$ corresponds to the complex between purified $\alpha 2 \mathrm{M}$ and recombinant IL- 6 .

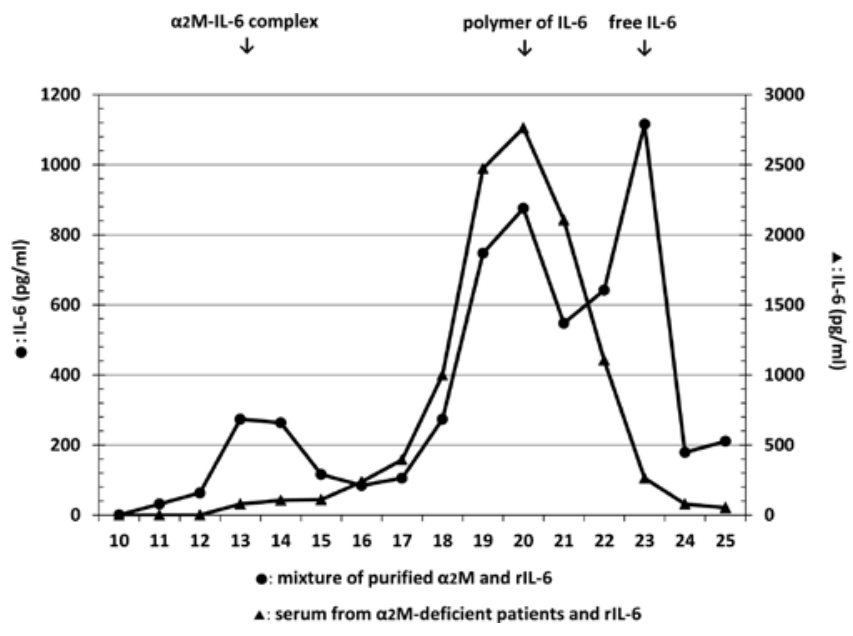

Figure 8. IL-6 elusion profiles of a mixture of $\alpha 2 \mathrm{M}$ and recombinant IL- 6 (rIL-6), and serum from patients with $\alpha 2 \mathrm{M}$ deficiency mixed with rIL-6. Using HPLC, the mixture of purified $\alpha 2 \mathrm{M}$ and rIL- 6 generated three peaks: the first peak at $800 \mathrm{kDa}$ corresponding to a $\alpha 2 \mathrm{M}-\mathrm{IL} 6$ complex; a second peak at $\sim 50 \mathrm{kDa}$ corresponding to a polymer of IL-6; and a third peak at $\sim 20 \mathrm{kDa}$ representing free IL-6.

the changes of acute inflammatory biomarkers in PCa patients with or without $\alpha 2 \mathrm{M}$ deficiency.

CRP is a plasma protein produced in liver cells by cytokine stimulation, mainly IL-6, but also interleukin-1 $\beta$ (IL-1 $\beta$ ) and tumor necrosis factor- $\alpha$ (TNF- $\alpha$ ) secreted from macrophages $(8,9)$. Serum CRP levels are increased in various conditions including infection, inflammation and tissue disturbance such as malignancy or myocardial infarction, but rarely in viral infection, multiple myeloma and non-active systemic lupus erythematosus $(6,15,16)$. It has been reported that CRP and SAA may be important prognostic markers for long-term survival in breast cancer patients (17). Fujikawa et al showed that elevated serum CRP levels are associated with tumor progression and poor prognosis of esophageal cancer (7). In recent years, the determination of high sensitivity CRP (hs-CRP) is possible due to the wide use of low concentration range measurements in 
routine clinical examination. It has been reported that hs-CRP reflects the degree of localized vascular inflammation and is a useful prognostic marker of cardiovascular events $(18,19)$.

SAA is a plasma protein produced in liver cells by cytokine stimulation mainly IL- $1 \beta$, as well as IL- 6 and TNF- $\alpha$, and it exists as a high density lipoprotein (HDL)-complex with a molecular weight of 200-400 kDa. SAA is generally increased in patients with viral infection and corticosteroid-treated patients, a characteristic that differs from CRP $(6,10)$. It has been hypothesized that the degree of change in serum SAA levels is larger as compared to CRP in various conditions such as infection, inflammation, malignancy and tissue disturbance, and IL1- $\beta$ stimulation of SAA production is hard to suppress by corticosteroid (10). Cocco et al showed that SAA may be a novel biomarker for endometrial cancer to monitor disease recurrence and response to therapy (20). It is also reported that extremely elevated plasma levels of CRP and SAA are high risk factors for development of gastric cancer (21).

IL-6 is the most sensitive inflammatory cytokine which promotes the production of both CRP and SAA in liver cells, similar to IL-1 $\beta$ and TNF- $\alpha$. It has been shown that serum IL-6 and CRP levels may be useful in the differentiation between diagnosis of pancreatic cancer and chronic pancreatitis (22). Kim et al reported that preoperative serum IL-6 and CRP levels may be markers of tumor invasion, lymph node metastasis and TNM stage (23). In the present study, CRP, SAA and IL-6 levels in serum were significantly increased in PCa patients without $\alpha 2 \mathrm{M}$ deficiency as compared with healthy controls and $\mathrm{PCa}$ patients with $\alpha 2 \mathrm{M}$ deficiency.

To further study the relationship between IL- 6 and $\alpha 2 \mathrm{M}$, we demonstrated and confirmed here that IL- 6 can easily complex with $\alpha 2 \mathrm{M}$ in vitro as detected by immunoblotting. Furthermore, using HPLC, we showed that the IL-6 elution profiles of a mixture of purified $\alpha 2 \mathrm{M}$ and rIL- 6 generated three peaks corresponding to the $\alpha 2 \mathrm{M}-\mathrm{IL}-6$ complex, polymer of IL- 6 and free IL-6. In contrast, a mixture of serum from $\alpha 2 \mathrm{M}$-deficient $\mathrm{PCa}$ patients and rIL- 6 did not demonstrate the peaks representing the $\alpha 2 \mathrm{M}-\mathrm{IL}-6$ complex and free IL- 6 . These results suggest that a function of $\alpha 2 \mathrm{M}$ is to bind and stabilize IL- 6 by forming a complex. Based on these findings, IL-6 may be unstable in PCa patients with $\alpha 2 \mathrm{M}$ deficiency, leading to decreased production of CRP and SAA in liver cells. This is supported by the evidence that the serum levels of $\alpha 2 \mathrm{M}$-dependent acute inflammatory biomarkers such as CRP, SAA and IL-6 were indeed decreased in PCa patients with $\alpha 2 \mathrm{M}$ deficiency.

Some other acute inflammatory biomarkers including $\alpha 1 \mathrm{AT}$, $\alpha 1 \mathrm{AG}$ and $\mathrm{CP}$ are also known to increase in various conditions. It has been reported that $\alpha 1 \mathrm{AT}$ may be a significant factor in the differential diagnosis of serous effusion in patients with malignant disease (24). Yildrim et al reported that $\alpha 1 \mathrm{AG}$ is a useful prognostic factor in addition to performance status in patients with primary lung cancer (25). It has been also shown that $\mathrm{CP}$ may be a reliable marker for prostate cancer where is not accompanied by elevation of serum PSA (26). Further, Kasprzyk et al have reported that $\alpha 1 \mathrm{AT}, \alpha 1 \mathrm{AG}$ and $\mathrm{CP}$ are useful prognostic factors in the risk assessment of non-small lung cancer recurrence after surgical management (27). In the present study, serum levels of $\alpha 1 \mathrm{AT}, \alpha 1 \mathrm{AG}$ and CP in PCa patients with and without $\alpha 2 \mathrm{M}$ deficiency were significantly higher than in healthy controls. Moreover, there was no significant difference in levels of these three factors between PCa patients with and without $\alpha 2 \mathrm{M}$ deficiency. These results suggest that $\alpha 1 \mathrm{AT}, \alpha 1 \mathrm{AG}$ and $\mathrm{CP}$ are acute inflammatory biomarkers which are independent of $\alpha 2 \mathrm{M}$ function as a carrier protein of IL-6.

In conclusion, the present study demonstrated that $\alpha 2 \mathrm{M}$ can stabilize IL- 6 by forming a complex, and in a mixture of serum from $\alpha 2 \mathrm{M}$-deficient PCa patients and rIL-6, the $\alpha 2 \mathrm{M}$-IL-6 complex and free IL- 6 could not be detected. Furthermore, serum levels of CRP, SAA and IL-6, which are dependent on $\alpha 2 \mathrm{M}$ function, were not increased in PCa patients with $\alpha 2 \mathrm{M}$ deficiency. Therefore, measurement of the acute inflammatory biomarkers (CRP, SAA and IL-6) that depend on $\alpha 2 \mathrm{M}$ in combination with those independent of $\alpha 2 \mathrm{M}$ function ( $\alpha 1 \mathrm{AT}, \alpha 1 \mathrm{AG}$ and $\mathrm{CP}$ ) in PCa patients may be an auxiliary indicator, together with PSA, to monitor PCa disease progression.

\section{Acknowledgements}

This study was supported by grants from the Ministry of Education, Culture, Sports and Technology (A11771512) and the Parent's Association Grant of Kitasato University, School of Medicine.

\section{References}

1. Matsuda T, Hirano T, Nagasawa S and Kishimoto T: Identification of $\alpha_{2}$-macroglobulin as a carrier protein for IL-6. J Immunol 142: $148-152,1989$

2. Kratzsch J, Selisko T and Birkenmeier G: Identification of transformed $\alpha_{2}$-macroglobulin as a growth hormone-binding protein in human blood. J Clin Endocrinol Metab 80: 585-590, 1995.

3. Ohtani H, Saito M and Koshiba K: Alpha-2-macroglobulin deficiency in patients with advanced prostate cancer. Oncology 42: 341-344, 1985.

4. Kanoh Y, Ohtani $\mathrm{H}$ and Koshiba K: Studies on $\alpha_{2}$-macroglobulin deficiency in association with cancer metastasis. Jap J Clin Immun 20: 30-43, 1997.

5. dos Anjos BL and Grotto HZ: Evaluation of C-reactive protein and serum amyloid $\mathrm{A}$ in the detection of inflammatory and infectious disease in children. Clin Chem Lab Med 48: 493-499, 2010.

6. Kanoh Y, Ohara T and Akahoshi T: Acute inflammatory biomarkers in cerebrospinal fluid as indicator of blood cerebrospinal fluid barrier damage in Japanese subjects with infectious meningitis. Clin Lab 57: 37-46, 2011.

7. Fujiwara H, Suchi K, Okamura H, Umehara S, Toda M, Shiozaki A, Kubota T, Ichikawa D, Okamoto K, Ochiai T, Kokuba Y, Sonoyama T and Otsuji E: Elevated serum CRP levels after indication chemoradiotherapy reflect poor treatment response in association with IL-6 in serum and local tumor site in patients with advanced esophageal cancer. J Surg Oncol 103: 62-68, 2011.

8. Yap SH, Moshage HJ, Hazenberg BP, Roelofs MH, Bijizet J, Limburg PC, Aarden LA and van Rijiswijk MH: Tumor necrosis factor (TNF) inhibits interleukin (IL)-1 and/or IL-6 stimulated synthesis of $\mathrm{C}$-reactive protein (CRP) and serum amyloid $\mathrm{A}$ (SAA) in primary cultures of human hepatocytes. Biochim Biophys Acta 19: 1091: 405-408, 1991.

9. Smith JW and McDonald TL: Production of serum amyloid A and C-reactive protein by HepG2 cells stimulated with combinations of cytokines or monocyte conditioned media: the effects of prednisolone. Clin Exp Immunol 90: 293-299, 1992.

10. Smith JW, Colombo JL and McDonald TL: Comparison of serum amyloid A and C-reactive protein as indicator of lung inflammation in corticosteroid treated and non-corticosteroid cystic fibrosis patients. J Clin Lab Anal 6: 219-224, 1992.

11. Spiessl B, Beahrs OH, Hermanek P, et al (eds): International Union Against Cancer. TNM Atlas. 3rd edition. 2nd revision. Springer-Verlag, New York, pp241-250, 1992.

12. Ida N, Sakurai S, Hosaka T, Hosoi K, Matsuura Y and Kohase M: An enzymelinked immunosorbent assay for the measurement of human interleukin-6. J Immunol Meth 133: 279-284, 1990. 
13. Laemmli KU: Cleavage of structural proteins during the assembly of the head of bacteriophage T4. Nature 227: 680-685, 1970.

14. Kasprzyk M, Dyszkiewicz W, Zwarun D, Lesniewska K and Wiktorowicz K: The assessment of acute phase proteins as prognostic factors in patients surgically treated for non-small cell lung cancer. Peumonol Alergo Pol 76: 321-326, 2008.

15. Bataille R, Boccadoro M, Klein B, Durie and Pileri A: C-reactive protein and beta-2 microglobulin produce a simple and powerful myeloma staging system. Blood 80: 733-737, 1992.

16. Firooz N, Albert D, Wallace D, Ishimori M, Berel D and Weisman M: High-sensitivity C-reactive protein and erythrocyte sedimentation rate in systemic lupus erythematous. Lupus 20: 588-597, 2011.

17. Pierce BL, Ballard-Barbrash R, Baumgartner RN, Neuhouser ML, Wener MH, Baumgartner KB, Gilliland FD, Sorensen BE, McTiernan A and Urich CM: Elevated biomarkers of inflammation are associated with reduced survival among breast cancer patients. J Clin Oncol 27: 3437-3444, 2009.

18. Imazio M, Brucato A, Maestroni S, Cumetti D, Dominelli A Natale $\mathrm{G}$ and Trinchero R: Prevalence of C-reactive protein elevation and time course of normalization in acute pericarditis: implication for the diagnosis, therapy, and prognosis of pericarditis. Circulation 213: 1092-1097, 2011.

19. Kablak-Ziembicka A, Przewlocki T, Sokolowski A, Tracz W and Podolec P: Carotid intima-media thickness, hs-CRP and TNF- $\alpha$ are independently associated with cardiovascular event risk in patients with atherosclerotic occlusive disease. Atherosclerosis 214: 185-190, 2011.

20. Cocco E, Bellone S, El-Sahwi K, Cargneluti M, Buza N Tavassoli FA, Schwartz PE, Rutherford TJ, Pecoreli S and Santin AD: Serum amyloid A: a novel biomarker for endometrial cancer. Cancer 116: 843-851, 2010.
21. Sasazuki S, Inoue M, Sawada N, Iwasaki M, Shimazu T, Yamaji $\mathrm{T}$ and Tsugane S: Plasma levels of C-reactive protein and serum amyloid A and gastric cancer in a nested case-control study; Japan Public Health Center-based prospective study. Carcinogenesis 31: 712-718, 2010.

22. Mroczko B, Groblewska M, Gryko M,Kedra B and Szmitkowski M Diagnostic usefulness of serum interleukin-6 (IL-6) and C-reactive protein $(\mathrm{CRP})$ in the differentiation between pancreatic cancer and chronic pancreatitis. J Clin Lab Anal 24: 256-261, 2010.

23. Kim DK, Oh SY, Kwon HC, Lee S, Kwon KA, Kim BG, Kim SG, Jang JS, Kim MC, Kim KH, Han JY and Kim HJ: Clinical significances of preoperative serum interleukin-6 and C-reactive protein in operable gastric cancer. BMC Cancer 9: 155, 2009.

24. Alexandrakis MG, Kyriakou D, Koutroubakis IE, Alexandraki R, Vlachonikolis IG and Eliopoulos GD: Assaying of tumor necrosis factor alpha, complement factors, and alpha-1-antitrypsin in the diagnosis of malignant serous effusions. Am J Clin Oncol 24: 562-565, 2001.

25. Yildirim A, Meral M, Kaynar H, Polat and Ucar EY: Relationship between serum levels of some acute-phase proteins and stage of disease and performance status in patients with lung cancer. Med Sci Monit 13: 195-200, 2007.

26. Fotiou K, Vaiopoulos G, Liakos K, Giannopoulos A, Mandalenaki K, Marinos G, Koritsiadis G, Sourdis J, Konstantinidou E and Konstantopoulos K: Serum ceruloplasmin as a marker in prostate cancer. Mineral Urol Nefrol 59: 407-411, 2007.

27. Kasprzyk M, Dyszkiewicz W, Zwarun D, Szydik S, Lesniewska K and Krzyzanowski K: The quantitative elevation of the serum acute phase proteins (APP) of patients undergoing a curative resection for non-small cell lung cancer (NSCLC). Przegl Lek 63: 936-940, 2006. 